\title{
Impacts of advanced physiotherapy: A narrative literature review
}

Anna H. Williams PhD, PGDip in Education and Professional Development

Professional Development Project Officer, Physiotherapy New Zealand, Wellington, New Zealand

Gill Stotter DipPhty, DipPhty (MT), PGDipPHC, NZCP Advanced Practitioner

Hutt Physiotherapy Centre, Lower Hutt, New Zealand; Physiotherapy New Zealand Professional Development Committee

Cheryl Hefford MPhty

Professional Advisor, Physiotherapy Board of New Zealand, Wellington, New Zealand

Jonathan Warren DHSC, MHSc, DipPhty

Professional Advisor, Physiotherapy Board of New Zealand, Wellington, New Zealand

Ben Darlow PhD, MSportPhysio, Physiotherapy Specialist

Senior Lecturer, Department of Primary Health Care \& General Practice, University of Otago, Wellington, New Zealand; Physiotherapy New Zealand Professional Development Committee

\section{ABSTRACT}

Changes to healthcare design and delivery involving advanced physiotherapy roles may help health systems to meet challenges imposed by ageing populations, long-term conditions and unsustainable healthcare costs. This narrative literature review examined recent peer-reviewed literature (2010-2017), including primary studies and systematic reviews, that investigated the impact of advanced physiotherapy on healthcare efficacy, efficiency, service design or perceptions (consumers or health professionals) of these advanced roles. Thirty-five studies were included that investigated advanced physiotherapy roles in primary care, emergency department, orthopaedic outpatient and rheumatology clinic contexts. Implementation of these roles was found to reduce waiting times for appointments, reduce length of stay, improve access to care, reduce other clinicians' workload in primary care and emergency departments, streamline orthopaedic surgeons' caseload, and improve patient satisfaction. Some studies observed patient recovery outcomes following advanced practice physiotherapist care, but none compared these to existing models of care. In addition, few studies explored non-musculoskeletal physiotherapy fields or the New Zealand context, and no studies investigated the impact on consumer choice. More clearly defined and consistent use of advanced physiotherapy roles within the literature would enable a better understanding of the potential impact on health care. Overall, evidence suggested that advanced physiotherapy roles may provide benefits to the public and health system when implemented in innovative, interdisciplinary and non-traditional ways.

\section{Williams, A. H., Stotter, G., Hefford, C., Warren, J., \& Darlow, B. (2019). Impacts of advanced physiotherapy: A narrative} literature review. New Zealand Journal of Physiotherapy, 47(3), 150-159. https://doi.org/10.15619/NZJP/47.3.03

Key Words: Delivery of Health Care, Health Workforce, Physical Therapy Specialty, Professional Role

\section{INTRODUCTION}

Ageing populations, increasing prevalence of long-term and co-morbid conditions, ongoing health inequity, growing healthcare costs, and workforce demands are driving international change in healthcare design and delivery. New models of service delivery are needed to achieve the best health outcomes for New Zealanders as the current health service is financially unsustainable (Ministry of Health, 2016). Advanced physiotherapy models and roles have been implemented in Australia (de Gruchy, Granger, \& Gorelik, 2015), Canada (Bath, Grona, \& Janzen, 2012) and the United Kingdom (Burn \& Beeson, 2014) to meet these challenges, demonstrating the potential of physiotherapy to contribute to new models of service delivery.

In New Zealand in 2017, a Physiotherapy Board of New Zealand working group ${ }^{1}$ explored the potential development of a regulated advanced scope of practice (Physiotherapy Board,
2017) to complement the existing general and specialist scopes of practice (Physiotherapy Board, n.d.). The Physiotherapy Board accepted the recommendations of the working group in 2018 and commenced developing a draft advanced/titled physiotherapist scope of practice (Physiotherapy Board, 2018).

The purpose of this narrative review was to investigate the impact of advanced physiotherapy on the public and the health system, and identify current gaps in the literature. A narrative review design enabled the exploration of diverse and heterogeneous studies related to this emerging area of physiotherapy practice (Greenhalgh, Thorne, \& Malterud, 2018).

In this review, the term "advanced physiotherapy" is used generically and encompasses advanced practice, extended scope and expanded scope, and an "advanced practice physiotherapist" (APP) refers to a physiotherapist working under any of these titles.

${ }^{1}$ An early iteration of this review was written for the working group. 


\section{METHODS}

Database searches were conducted for relevant peer-reviewed articles, using the search terms "physiotherap* "or "physical therap*", and "advanced practice", "expanded practice" or "extended practice". Databases searched were CINAHL Plus with full text, Cochrane Library (Wiley), Directory of Open Access Journals, Google Scholar, Health Reference Centre Academic (Gale), Informa Healthcare Journals, Medline/PubMed, OneFile, PEDro, ProQuest variants, Rehabilitation and Sports Medicine, Science Direct (Elsevier), Scopus, SPORTDiscus with full text, SwePub, and Wiley (CrossRef). Other potentially relevant literature was identified through bibliography searches of included articles and expert recommendation.

Studies were considered from a variety of contexts (primary care, emergency departments, orthopaedic outpatients and specialist doctors). Findings relating to access to care, quality and timeliness of care, service and economic efficiencies, and stakeholder (health professional and consumer) perspectives regarding advanced physiotherapy were examined.

Studies were included if they reported research findings (primary studies and systematic reviews) investigating the impact of advanced physiotherapy on healthcare efficacy, efficiency, service design, patient outcomes or perceptions (public or health professionals) of APPs, and were published in English between January 2010 and September 2017. Studies set in military deployment contexts (e.g. Afghanistan) were excluded as these were considered to relate poorly to the general healthcare delivery.

Duplicate citations were removed from search results. Titles and abstracts of citations were then screened for relevance to the inclusion criteria by one of two reviewers. For papers that appeared to meet the eligibility criteria, and those for which it was unclear from the title and abstract whether they met the criteria, full papers were retrieved and evaluated. A final decision about eligibility was then made by agreement between the reviewers. Data and themes were extracted from the selected papers by one reviewer with assistance from the other.

\section{RESULTS}

Through the literature searches, 103 titles were identified after duplicates had been removed. Seventy-one were excluded (two from military deployment contexts) based on title and abstract, 32 full-text articles were read, and 22 were included in the literature review (Figure 1). Also included were seven papers identified from bibliography searches and six from expert recommendation. In total, 35 eligible studies (five systematic reviews and 30 primary studies) were included in the review (Table 1). As indicated in Table 1, the included primary study by Kennedy, Robarts, and Woodhouse (2010) had been appraised within two of the included systematic reviews. The included primary study by Razmjou et al. (2013) had also been appraised in a different (also included) systematic review. Care was taken to ensure that the findings from these primary studies were not overemphasised due to their inclusion in the systematic reviews.

Impacts on the public and the health system

Overall, common themes emerged from the literature, including reduced wait times, expedited access to care and positive impact on other clinicians' workloads. These were mainly in relation to musculoskeletal conditions. These themes will be discussed in relation to primary care, emergency department, orthopaedic outpatient and rheumatology clinic contexts.

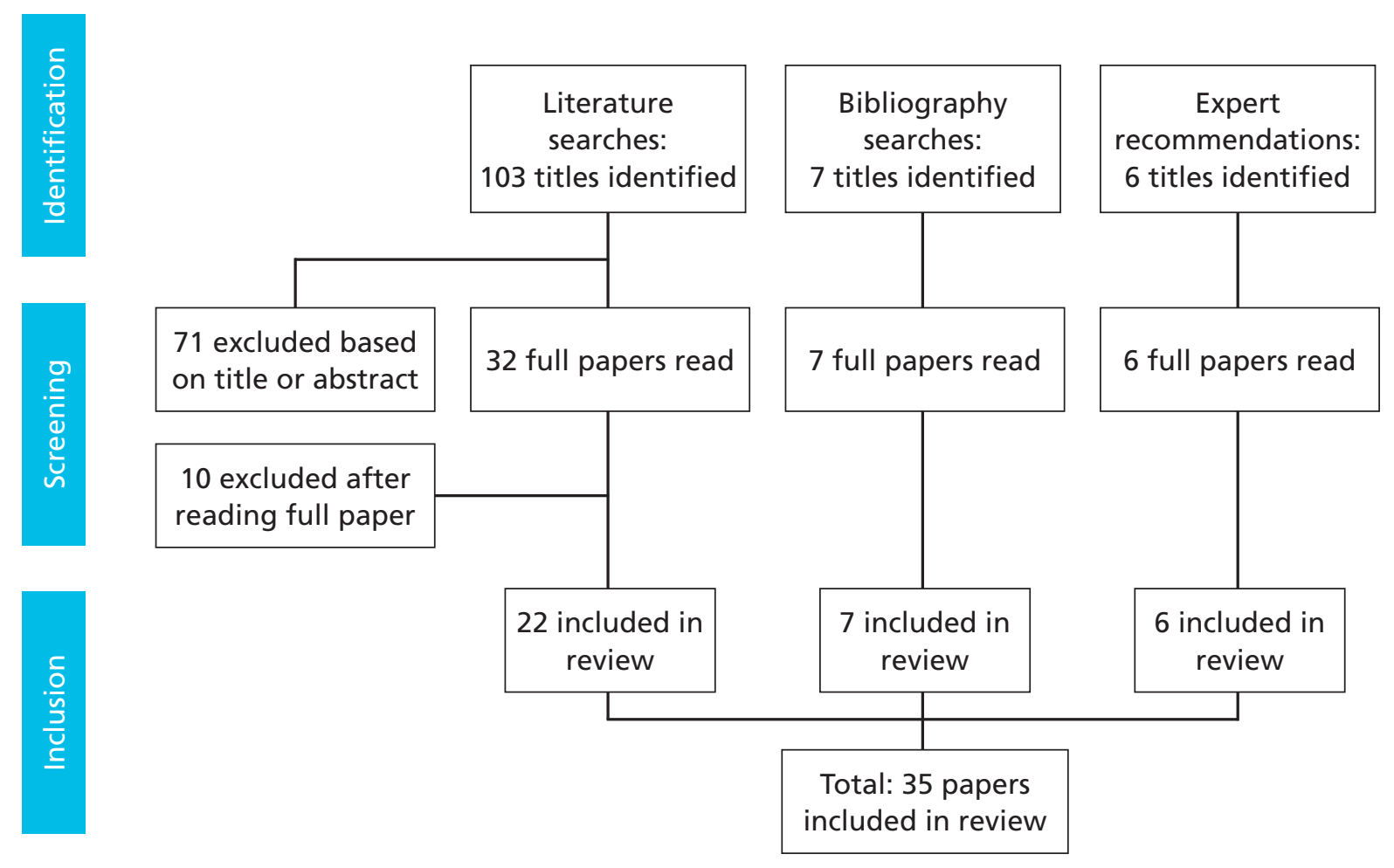

Figure 1: Literature identification, screening and inclusion-process results 
Table 1: Literature included in this review

\begin{tabular}{|c|c|c|c|c|}
\hline Reference & Country & Setting & Sample size ${ }^{a}$ & Study design and description \\
\hline Bath et al. (2012) & Canada & $\begin{array}{l}\text { Orthopaedic, } \\
\text { spinal triage }\end{array}$ & $\begin{array}{l}\mathrm{n} \text { (different variables) }= \\
336-672 \text { patients, with } \\
\mathrm{n}(\text { full data })=299\end{array}$ & $\begin{array}{l}\text { Ex post facto observational study evaluating APPs' } \\
\text { diagnoses of primary care referrals to surgeon }\end{array}$ \\
\hline $\begin{array}{l}\text { Burn \& Beeson } \\
(2014)\end{array}$ & UK & $\begin{array}{l}\text { Orthopaedic, } \\
\text { triage }\end{array}$ & $\begin{array}{l}\mathrm{n}(\text { screened referrals })= \\
1,395 \text { patients; } \\
\mathrm{n}(\text { screened to } \mathrm{APP})=273\end{array}$ & $\begin{array}{l}\text { Quantitative evaluation of an APP's screening, } \\
\text { diagnoses and management of primary care } \\
\text { referrals to surgeon }\end{array}$ \\
\hline $\begin{array}{l}\text { de Gruchy et al. } \\
\text { (2015) }\end{array}$ & Australia & $\begin{array}{l}\text { Emergency } \\
\text { department }\end{array}$ & $\mathrm{n}=1017$ patients & $\begin{array}{l}\text { Single-site prospective observational study } \\
\text { comparing APP management with physician } \\
\text { management of categories 3-5 musculoskeletal } \\
\text { presentations }\end{array}$ \\
\hline $\begin{array}{l}\text { Desjardins- } \\
\text { Charbonneau et al. } \\
\text { (2016) }\end{array}$ & Canada & Community & $\begin{array}{l}\mathrm{n}=513 \text { consumers } \\
\text { (university community) }\end{array}$ & $\begin{array}{l}\text { Descriptive qualitative study exploring consumer } \\
\text { perceptions about physiotherapists and APPs } \\
\text { as primary care providers for treatment of } \\
\text { musculoskeletal presentations }\end{array}$ \\
\hline $\begin{array}{l}\text { Desmeules et al. } \\
(2012)\end{array}$ & & Musculoskeletal & $\mathrm{n}($ total $)=4,752$ patients & $\begin{array}{l}\text { Systematic literature review evaluating APP care } \\
\text { and management of patients with musculoskeletal } \\
\text { disorders (publication: 1980-2011; original } \\
\text { qualitative research; } 16 \text { studies reviewed, } \\
\text { comprising seven only appraised in this review, plus } \\
\text { Kennedy et al., 2010, and eight appraised in other } \\
\text { reviews: four in Oakley \& Shacklady, 2015; two } \\
\text { in Saxon et al., 2014; one in Oakley \& Shacklady, } \\
\text { 2015, and Saxon et al., 2014; one in Oakley \& } \\
\text { Shacklady, 2015, and Stanhope, Grimmer-Somers } \\
\text { et al., 2012) }\end{array}$ \\
\hline $\begin{array}{l}\text { Desmeules et al. } \\
\text { (2013) }\end{array}$ & Canada & $\begin{array}{l}\text { Orthopaedic } \\
\text { outpatients }\end{array}$ & $\mathrm{n}=120$ patients & $\begin{array}{l}\text { Mixed methods evaluation comparing diagnosis } \\
\text { and care recommendations by an APP with those } \\
\text { of surgeons }\end{array}$ \\
\hline Exton et at. (2014) & $\mathrm{NZ}$ & $\begin{array}{l}\text { Emergency } \\
\text { department }\end{array}$ & Not reported & $\begin{array}{l}\text { Evaluation of six-month pilot project involving } \\
\text { allied health practitioners, including APPs, within } \\
\text { an interdisciplinary team }\end{array}$ \\
\hline $\begin{array}{l}\text { Goodwin \& } \\
\text { Hendrick (2016) }\end{array}$ & UK & General practice & $\begin{array}{l}n \text { (total) }=600 \text { patients, } \\
\text { comprising } n(\text { APPs }) \\
=500 ; n(G P s)=100\end{array}$ & $\begin{array}{l}\text { Dual-site pragmatic prospective evaluation } \\
\text { comparing APPs and GPs as primary care } \\
\text { practitioner for musculoskeletal presentations }\end{array}$ \\
\hline $\begin{array}{l}\text { Harding et al. } \\
(2015)\end{array}$ & Australia & $\begin{array}{l}\text { Emergency } \\
\text { department }\end{array}$ & $\mathrm{n}=25$ patients & $\begin{array}{l}\text { Dual-site qualitative descriptive observational study } \\
\text { evaluating patient experience and satisfaction with } \\
\text { APP care for musculoskeletal presentations }\end{array}$ \\
\hline Hawke et al. (2013) & Canada & $\begin{array}{l}\text { Rheumatology, } \\
\text { axial } \\
\text { spondyloarthritis }\end{array}$ & $\mathrm{n}=20$ patients & $\begin{array}{l}\text { Single-site evaluation comparing APP screening } \\
\text { versus rheumatologist screening of inflammatory } \\
\text { bowel disease patients }\end{array}$ \\
\hline Jones et al. (2015) & Wales & Cross-sectoral & $\begin{array}{l}\mathrm{n}=67 \text { healthcare } \\
\text { professionals }\end{array}$ & $\begin{array}{l}\text { Qualitative study exploring perceptions of various } \\
\text { professional groups about advanced practitioner } \\
\text { roles across different health professions }\end{array}$ \\
\hline $\begin{array}{l}\text { Kennedy et al. } \\
(2010)^{b}\end{array}$ & Canada & $\begin{array}{l}\text { Orthopaedic, } \\
\text { hip and knee } \\
\text { replacement } \\
\text { review clinic }\end{array}$ & $\begin{array}{l}n=123 \text { patients, } \\
\text { comprising } n(A P P) \\
=63 ; n(\text { surgeon })=60\end{array}$ & $\begin{array}{l}\text { Qualitative study comparing patient satisfaction } \\
\text { with APP-led versus orthopaedic surgeon-led } \\
\text { follow-up care }\end{array}$ \\
\hline $\begin{array}{l}\text { Kerridge-Weeks \& } \\
\text { Langridge (2016) }\end{array}$ & UK & $\begin{array}{l}\text { Orthopaedic, } \\
\text { spinal triage }\end{array}$ & $\mathrm{n}=100$ patients & $\begin{array}{l}\text { Service evaluation of an APP's diagnostic triage-to- } \\
\text { care pathways }\end{array}$ \\
\hline
\end{tabular}




\begin{tabular}{|c|c|c|c|c|}
\hline Reference & Country & Setting & Sample size ${ }^{a}$ & Study design and description \\
\hline $\begin{array}{l}\text { Lefmann \& } \\
\text { Sheppard (2014) }\end{array}$ & Australia & $\begin{array}{l}\text { Emergency } \\
\text { department }\end{array}$ & $\begin{array}{l}n=6 \text { healthcare } \\
\text { professionals }\end{array}$ & $\begin{array}{l}\text { Single site qualitative study exploring perceptions } \\
\text { of doctors, nurses and physiotherapists regarding } \\
\text { advanced physiotherapy role }\end{array}$ \\
\hline
\end{tabular}

$\begin{array}{ll}\begin{array}{l}\text { Mackay et al. Canada } \\ \text { (2012) }\end{array} & \begin{array}{l}\text { Orthopaedic } \\ \text { outpatients, hip } \\ \text { and knee arthritis }\end{array}\end{array}$

Single group pre- and post-intervention study investigating patients' use of self-management strategies, and comparing patients' exercise behaviour and self-efficacy from baseline to followup

Mallett et al. (2014) UK

McClellan et al. UK (2012)

McClellan et al. UK (2013)

Morris et al. (2014) Australia

Morris et al. (2015) Australia

Naik (2016)

NZ

Napier et al. (2013) Canada

O Mir et al. (2016) Republic of Ireland

Oakley \& Shacklady

(2015)
Referral to NHS musculoskeletal physiotherapy

Emergency department

Emergency department

Tertiary hospital

$\mathrm{n}=8$ stakeholders

Emergency department

Orthopaedic, spinal screening

Orthopaedic, knee and shoulder triage

Orthopaedic, paediatric triage

$\mathrm{n}=2,650$ patients

Musculoskeletal

$\mathrm{n}=194$ patients, $n(G P)=89$

$\mathrm{n}=372$ patients, comprising $\mathrm{n}(\mathrm{APP})=126$, $n$ (nurses) $=123$,

$\mathrm{n}$ (doctors) $=123$ professionals) $=3$, $\mathrm{n}$ (patients) $=11$

Not reported

$\mathrm{n}=45$ patients

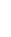

Repeated measure prospective cohort study comprising $n$ (self) $=105$; evaluating self-referral versus GP-referral pathways

$\mathrm{n}=372$ patients, as per McClellan et al. (2012)

Assessment/ management Mixed methods, single site prospective component: $\mathrm{n}=13,495$ patients (836 treated by APP); Perspective component: $n$ (healthcare

$\mathrm{n}($ total $)=2,344$ patients
Single site randomised pragmatic trial of equivalence comparing clinical effectiveness of soft tissue injury management by APPs, emergency nurse practitioners and doctors

Single site randomised pragmatic trial of equivalence comparing the cost-effectiveness of soft tissue injury management by APPs, emergency nurse practitioners and doctors

Cross-sectional qualitative study exploring stakeholders' perspectives about a workforce redesign involving advanced physiotherapy roles

observational longitudinal study comparing "fast track" assessment and management of categories 4 and 5 musculoskeletal presentations by an APP, advanced scope nurses, nurse practitioners and doctors

Evaluation of APP screening of GP referrals to orthopaedic surgeon

Prospective observational study comparing diagnostic agreement rate between an APP (triage) and surgeon, and surgical conversion rates between APP referrals and primary care provider referrals to surgeon

Prospective longitudinal cohort study evaluating efficacy of APP triage and care of non-surgical candidates

Systematic literature review evaluating APPs in musculoskeletal triage (publication: 1989-2014; 14 studies reviewed, comprising five only appraised in this review, plus Razmjou et al., 2013, and eight appraised in other reviews: four in Desmeules et al., 2012; one in Saxon et al., 2014; one in Stanhope, Grimmer-Somers et al., 2012; one in Desmeules et al., 2012 and Saxon et al., 2014; one in Desmeules et al., 2012, and Stanhope, Grimmer-Somers et al., 2012) 


\begin{tabular}{|c|c|c|c|c|}
\hline Reference & Country & Setting & Sample size ${ }^{a}$ & Study design and description \\
\hline $\begin{array}{l}\text { Passalent et al. } \\
\text { (2015) }\end{array}$ & Canada & $\begin{array}{l}\text { Rheumatology, } \\
\text { axial } \\
\text { spondyloarthritis }\end{array}$ & $\mathrm{n}=57$ patients & $\begin{array}{l}\text { Study comparing APPs' and rheumatologists' } \\
\text { clinical impressions and MRI recommendations }\end{array}$ \\
\hline Phillips et al. (2012) & Wales & $\begin{array}{l}\text { Occupational } \\
\text { health services }\end{array}$ & $\begin{array}{l}n=486 \text { (baseline); } \\
n=264 \text { (treatment-end); } \\
n=199 \text { (follow-up) }\end{array}$ & $\begin{array}{l}\text { Pragmatic cohort study evaluating cost- } \\
\text { effectiveness and feasibility of three-tier self- } \\
\text { referral pilot physiotherapy service }\end{array}$ \\
\hline $\begin{array}{l}\text { Razmjou et al. } \\
(2013)^{c}\end{array}$ & Canada & $\begin{array}{l}\text { Orthopaedic, } \\
\text { shoulder triage }\end{array}$ & $\begin{array}{l}n(\text { total })=494 \text { patients, } \\
\text { comprising } \\
n(1)=100, n(2)=200 \\
n(3)=194\end{array}$ & $\begin{array}{l}\text { Single site prospective study comparing an APP's } \\
\text { and a surgeon's (1) diagnostic and management } \\
\text { recommendation agreement, (2) wait times, and } \\
\text { (3) patient satisfaction; separate samples for each } \\
\text { component }\end{array}$ \\
\hline
\end{tabular}

Samsson et al. Sweden Orthopaedic triage $n=163$ patients:

(2016) n (APP) $=83$,

$\mathrm{n}$ (surgeon) $=80$

Samsson \& Larsson Sweden Orthopaedic $n=203$ patients:

(2014) screening $\mathrm{n}(\mathrm{APP})=102$,

$\mathrm{n}$ (surgeon) $=101$

Saxon et al. (2014)

Extended scope $n$ (total) $=2,453$ (mix of roles across a health professionals and range of contexts patients)

Randomised controlled trial comparing patient perceptions of quality of care of APP triage versus standard practice

Randomised controlled trial comparing APP screening of initial referrals to orthopaedic consultation with standard practice

Systematic literature review of extended scope roles in physiotherapy, occupational therapy and speech pathology (publication: 2005-2013; 21 studies reviewed, comprising 15 only appraised in this review, plus Kennedy et al., 2010, and five appraised in other reviews: two in Desmeules et al., 2012; one in Oakley \& Shacklady, 2015; one in Stanhope, Beaton et al., 2012; one in Desmeules et al., 2012, and Oakley \& Shacklady, 2015)

Schulz et al. (2016) Australia

Stanhope, Beaton et al. (2012)

Stanhope, GrimmerSomers et al. (2012) department

Inflammatory arthropathies

Orthopaedic settings
Emergency

$\mathrm{n}=117$ patients (limb: 88, Dual site prospective study comparing patient back: 29)

$\mathrm{n}($ total $)=$ undisclosed outcomes (lower limb soft tissue injuries or acute low back pain presentations) for APPs versus other health professionals

Systematic literature review into APPs managing patients with inflammatory arthropathies (publication: 2002-2012; four studies reviewed, including one appraised by Saxon et al., 2014)

Systematic literature review into advanced physiotherapy roles in orthopaedic settings (publication: open-ended; 12 studies reviewed, comprising 10 only appraised in this review, plus one appraised by Oakley \& Shacklady, 2015, and one by Desmeules et al., 2012, and Oakley \& Shacklady, 2015)

Rheumatology, $\mathrm{n}=325$ patients arthritis
Mixed method cross-sectional evaluation of patient satisfaction with APP and occupational therapist care

Qualitative study exploring perceptions of health professionals of advanced physiotherapy roles

Warmington et al. Canada (2015) (2016)

Note: APP, advanced practice physiotherapist; GPs, general practitioners; MRI, magnetic resonance imaging; NHS, National Health Service; n, number; NZ, New Zealand; UK, United Kingdom

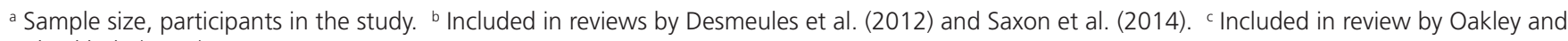
Shacklady (2015)
} 


\section{Primary care}

Three primary studies evaluated advanced physiotherapy roles in primary care contexts (Goodwin \& Hendrick, 2016; Mallett, Bakker, \& Burton, 2014; Phillips et al., 2012). Goodwin and Hendrick (2016) found that APPs acting as first point of care for musculoskeletal complaints, instead of general practitioners (GPs), could provide safe and clinically effective care (in terms of self-reported improvements in Global Rating of Change and EQ5D-5L measures) at a lower cost per episode of care (although a comparison of clinical efficacy between GPs and APPs was not conducted)

Mallett et al. (2014) compared a novel self-referral pathway involving an initial telephone triage appointment with an APP to publicly provided physiotherapy with the standard GP referral pathway. Self-referral provided an effective alternative with shorter wait times for treatment and with considerable cost savings (a mean saving of $£ 36.42$ per patient per episode of care) compared with the standard pathway. Cost savings were due to greater initial appointment attendance rates and fewer patient contacts. Reduction in wasted appointments projected annual savings of 0.75 to 1.23 full-time equivalents for the selfreferral pathway (Mallett et al., 2014).

Phillips et al. (2012) evaluated the cost-effectiveness and feasibility of a self-referral pilot occupational health physiotherapy service led by APPs. Statistically significant improvements were seen in all target variables (clinical: pain intensity Visual Analogue Scale, General Health Questionnaire psychological distress, EQ-5D quality of life, Short Form Health Survey [SF12] mental and physical health subscales; psychosocial: pain catastrophising, work and physical activity fear and avoidance; work-related: sickness absence, work performance) from baseline to end of treatment, and to the three-month follow-up. They found that the cost of the selfreferral service would need to increase by $160 \%$ before it fell outside the value-for-money range, suggesting that initiatives of this type may provide clinical, psychosocial and work-related cost-effective benefits.

\section{Emergency departments}

Six primary studies and one systematic review investigated advanced physiotherapy roles in emergency departments (de Gruchy et al., 2015; Desmeules et al., 2012; Exton et al., 2014; McClellan, Cramp, Powell, \& Benger, 2012; McClellan, Cramp, Powell, \& Benger, 2013; Morris, Vine, \& Grimmer, 2015; Schulz et al., 2016). de Gruchy et al. (2015), Desmeules et al. (2012) and Morris et al. (2015) found that APPs' initial management of less serious musculoskeletal presentations assisted in meeting waiting-time and length-of-stay targets, expediting access to care for those patients. The advanced physiotherapy role was found to reduce the less serious musculoskeletal caseload for other clinicians in the emergency department medical team, enabling them to focus on medical and more serious musculoskeletal presentations (de Gruchy et al., 2015; Morris et al., 2015; Schulz et al., 2016). McClellan et al. (2012) found that APP management of peripheral soft tissue injuries achieved equivalent functional and time-off-work outcomes eight weeks following treatment when compared to other medical professionals in the team. Likewise, Schulz et al. (2016) found that APP management of musculoskeletal injuries and pain resulted in similar functional outcomes (self-reported and delays in return to work or sport) and pain-related outcomes to those achieved by other health professionals, but with less imaging ordered or opioids administered.

Economic evaluations of advanced physiotherapy roles in emergency departments returned inconsistent results. Exton et al. (2014) found that identified cost savings resulting from prevented admissions outweighed the cost of employing APPs as primary contact practitioners. McClellan et al. (2013) concluded that APP care was equivalent in cost to doctor care when comparing soft tissue injury management cost-effectiveness across different members of the medical team. Similarly, in their systematic review, Desmueles et al. (2012) reported no significant differences in cost between APP and standard care.

\section{Orthopaedic outpatients}

Ten primary studies examined APP involvement in orthopaedic outpatient contexts (Bath et al., 2012; Burn \& Beeson, 2014; Desmeules et al., 2013; Kerridge-Weeks \& Langridge, 2016; MacKay, Davis, Mahomed, \& Badley, 2012; Naik, 2016; Napier, McCormack, Hunt, \& Brooks-Hill, 2013; O Mir et al., 2016; Razmjou et al., 2013; Samsson \& Larsson, 2014), as did four systematic reviews (Desmeules et al., 2012; Oakley \& Shacklady, 2015; Saxon, Gray, \& Oprescu, 2014; Stanhope, GrimmerSomers, Milanese, Kumar, \& Morris, 2012). Shorter wait times and expedited access to care were reported by multiple studies. In those evaluating APP-led screening of primary care referrals to orthopaedic surgeons, a high proportion (69\%-90\%) of initial referrals were found by APPs to be inappropriate or were managed independently by the APP (Bath et al., 2012; Burn \& Beeson, 2014; Kerridge-Weeks \& Langridge, 2016; Naik, 2016; O Mir et al., 2016). APP referrals for surgical consultation were likely to receive orthopaedic interventions $(70-80 \%$ : Bath et al., 2012) and considerably more likely to receive such interventions than referrals by primary care providers referralsBurn and Beeson (2014): 75\% versus 57\%; Napier et al. (2013): 90\% versus $22 \%$; Samsson and Larsson (2014): $55 \%$ versus $25 \%$. The APP identification of inappropriate surgical referrals expedited access to non-surgical management. Significantly, shorter waiting times were found for APP-led screening than for standard practice (Naik, 2016; O Mir et al., 2016; Razmjou et al., 2013; Samsson \& Larsson, 2014; Stanhope, GrimmerSomers, et al., 2012).

Removing non-surgical candidates from surgeons' workloads also reduced the surgical consultation wait time for appropriate referrals (Bath et al., 2012; Naik, 2016; O Mir et al., 2016; Razmjou et al., 2013; Samsson \& Larsson, 2014; Saxon et al., 2014). However, Burn and Beeson (2014) cautioned that the removal of candidates from waitlists might perversely stimulate GP referrals; without a reduction in waitlist capacity, GPs may refer more patients for surgical consultation as the length of waitlists decreased.

Diagnostic inter-rater agreement between APPs and orthopaedic surgeons was found to be high for knee and hip presentations by Desmeules et al. (2013): Kappa $(\mathrm{k})=0.86$; and by Razmjou et al. (2013): $k=0.63-0.86$ for major diagnostic categories of shoulder presentation. In three systematic reviews, APPs' diagnostic accuracy for musculoskeletal presentations (e.g. knee 
or shoulder impairments) was comparable to that of surgeons', or high-as compared to subsequent arthroscopy or magnetic resonance imaging findings (Desmeules et al., 2012; Oakley \& Shacklady, 2015; Stanhope, Grimmer-Somers et al., 2012).

High levels of agreement in surgical and non-surgical treatment recommendations between APPs and orthopaedic surgeons have been reported, further indicating that using APPs for orthopaedic screening does not reduce care quality-Desmeules et al. (2013) and Napier et al. (2013): $\mathrm{k}=0.77$ for treatment approach; Razmjou et al. (2013): $\mathrm{k}=0.75$ for indications for surgery. In their systematic review, Stanhope, GrimmerSomers et al. (2012) reported a finding that the accuracy of identification of surgical candidates was higher for the APP $(100 \%)$ than for the orthopaedic team doctors (79\%).

Orthopaedic screening by APPs has been found to produce cost benefits (Burn \& Beeson, 2014; Desmeules et al., 2012; Stanhope, Grimmer-Somers, et al., 2012). Although APP consultation adds cost for those referred on for surgical assessment, this is offset by savings created by high proportions of inappropriate referrals triaged directly to non-surgical management (Burn \& Beeson, 2014). The systematic reviews of Desmeules et al. (2012) and Stanhope, Grimmer-Somers, et al. (2012) demonstrated evidence that the use of APPs in orthopaedic contexts resulted in cost savings.

Samsson and Larsson (2014) found significantly more nonsurgical patients were referred to physiotherapy by the APP than by the surgeon, suggesting that the APP may be more aware of the potential benefits of physiotherapy treatment than the surgeon. These findings implied that APP screening could expedite access to both surgical and non-surgical management options.

Mackay et al. (2012) studied the results of multimodal management of non-surgical candidates six weeks post-APP screening. Patients reported spending more time stretching (50\%) and more time walking or exercising (40\%), and significant increases in self-efficacy (with a medium effect size). These findings suggest that APP management can enhance the use of active rehabilitation strategies for non-surgical candidates. One study reported improvements in chronic disease self-efficacy scores after APP management, although the findings were attenuated by a lack of comparison with other care pathways or patient groups (Saxon et al., 2014). No studies were found comparing patient outcomes of APP care with other care pathways

\section{Rheumatology clinics}

In their systematic review, Stanhope, Beaton, GrimmerSomers, \& Morris (2012) appraised studies of APPs managing inflammatory arthropathy patients. However, all studies were deemed to be of low quality, and none reported measures of the effectiveness of APP management in terms of health outcomes or economic evaluations.

Hawke et al. (2013) evaluated an APP-led screening programme for patients with suspected axial spondyloarthritis and found that it may assist in reducing the wait time from referral to assessment. Passalent et al. (2015) found the agreement rates between APPs and rheumatologists in their clinical impression of axial spondyloarthritis and magnetic resonance imaging recommendation to be comparable within and between the two professions (although inter-observer agreement rates were not high; inter-rater agreement for clinical impression was moderate: $\mathrm{K}=0.52$; inter-rater agreement for recommendation of imaging was fair: $\mathrm{k}=0.37$ ). Passalent et al. (2015) concluded that APPs could assist in improving rates of early detection and earlier access to care.

\section{Stakeholder perspectives \\ Consumers}

Sixteen studies explored consumer perspectives in a variety of contexts. Three of these studies examined patient perspectives of APPs in primary care and found high levels of patient satisfaction with and support for APPs in primary care roles (Desjardins-Charbonneau, Roy, Thibault, Ciccone, \& Desmeules, 2016; Goodwin \& Hendrick, 2016). Mallett et al. (2014) found that patients who self-referred to APPs reported greater satisfaction with wait times for a physiotherapy appointment and a significantly higher perception of active involvement than those referred to physiotherapy by their GP.

Six studies evaluated patient satisfaction in emergency departments. Desmeules et al. (2012) and Morris et al. (2015) found high levels of satisfaction with APP care of musculoskeletal presentations, and Saxon et al. (2014) reported higher patient satisfaction with APP care than that of other health professionals for soft tissue injuries. Harding, Prescott, Block, O'Flynn, \& Burge (2015) found that patients were satisfied with the timing and efficiency of APP care and had confidence in the APPs' knowledge and skills. In one study, patient satisfaction on discharge was higher with APP care than for other health professionals, with the authors surmising that this may be due to the education and advice given (Schulz et al., 2016). Exton, Holmes, Scranney and Hollebon (2014) reported an "overwhelmingly positive" response from patients who were treated by the APP as primary contact practitioner.

Patient satisfaction with APP involvement in orthopaedic contexts was evaluated by nine studies. Four found levels of patient satisfaction with APP care to be high (Desmeules et al., 2012; Naik 2016; Napier et al., 2013; Oakley \& Shacklady, 2015), and three reported that patients were more satisfied with APP care than that provided by surgeons (Desmeules et al., 2013; Razmjou et al., 2013; Samsson, Bernhardsson \& Larsson, 2016). Kennedy et al. (2010) found that patient satisfaction with APP care post-orthopaedic surgery was comparable to that provided by surgeons. Other studies reported by Saxon et al. (2014) mirrored findings by Kennedy and colleagues.

In the context of arthritis care, Warmington et al. (2015) found that patient satisfaction with APP care was comparable to or greater than arthritis care previously received from other professionals.

\section{Health professionals}

The perspectives of health professionals regarding advanced physiotherapy roles were investigated by six studies (Exton et al., 2014; Lefmann \& Sheppard, 2014; Morris et al., 2014; Morris 
et al., 2015; Oakley \& Shacklady, 2015; Wiles \& Milanese, 2016). A seventh study (Jones, Powell, Watkins, \& Kelly, 2015) explored health professionals' perspectives of advanced practice roles across diverse healthcare professions (including physiotherapy). Aspects considered important for advanced physiotherapy roles were clearly defined formal training and qualifications, common terminology, clear role definition, and negotiation of shifting professional boundaries (Jones et al., 2015; Lefmann \& Sheppard, 2014; Morris et al., 2014; Wiles \& Milanese, 2016). The need for legislative changes to enable or support the implementation of advanced physiotherapy roles was identified (Morris et al., 2014; Wiles \& Milanese, 2016). Positive sentiments about contributions that APPs could make to meeting healthcare needs were also expressed (Jones et al., 2015; Wiles \& Milanese, 2016), including in emergency departments (Exton et al., 2014; Lefmann \& Sheppard, 2014; Morris et al., 2015). GPs were also satisfied with APP care (Oakley \& Shacklady, 2015).

\section{DISCUSSION}

Use of APPs was found to create a number of benefits for health systems and consumers. These included reduced waiting times for appointments, reduced length of stay, improved access to care, improved onward referral, reduced musculoskeletal caseload for other clinicians in primary care and emergency departments, streamlined orthopaedic surgeon caseload, and improved patient satisfaction in a variety of contexts. Economic evaluations indicated that advanced physiotherapy roles were either cost saving or of equivalent cost compared to traditional models. Overall, these findings indicate that utilising APPs in innovative models of care has potential benefits of shorter patient pathways, better decisions regarding onward referral and efficiencies of service. Care provided by APPs was found to be safe and effective, and no evidence was found of harmful impacts of APP care or advanced physiotherapy roles to the public or health system.

Understanding the perspectives of different stakeholders is important when considering adjustments to traditional practice boundaries. The public (patients) would be directly impacted by the implementation of innovative models of care and the use of APPs in non-traditional roles. A number of studies found that patients consider APP involvement in various roles to be acceptable and were satisfied with APP care (e.g. Goodwin \& Hendrick, 2016; Harding et al., 2015; Napier et al., 2013; Warmington et al., 2015). A recognised system denoting APPs (and indicating areas of APPs' expertise) would likely assist consumers to identify physiotherapists who best meet their health needs. This would be of particular relevance in jurisdictions (such as New Zealand) where consumers are able to self-refer to physiotherapy, often to the physiotherapist of their choice.

Other health professionals would also be impacted by the implementation of advanced physiotherapy roles. While other health professionals believed such roles could be beneficial, they perceived a need for clarity about the scope and focus of advanced physiotherapy roles. This is consistent with the emphasis on role clarification that is included in established interprofessional practice frameworks. Role clarification is a key competency domain required for effective interprofessional collaboration and practice (Canadian Interprofessional Health Collaborative, 2010). Inconsistencies in advanced physiotherapy roles and changes to professional practice boundaries challenged such role implementation. Improved understanding, credibility and acceptance of APP roles between health professionals would be vital for effective enactment.

Results from economic analyses of APPs working in nontraditional roles were context dependent. Findings in primary care and orthopaedic contexts suggested that utilisation of APPs could provide economic efficiencies. For example, screening programmes in orthopaedic outpatients may offer sizable cost savings across the patient pathway (Burn \& Beeson, 2014), although the economic benefits would likely be contingent on the quality of initial referrals. Presumably, such programmes would be most cost-effective in situations where the current surgical conversion rate was low. Economic analyses of advanced physiotherapy roles in emergency departments were inconclusive, and further robust evaluations are needed. With our search strategy, we were not able to find any examples of economic analyses of advanced physiotherapy roles in rheumatology contexts.

\section{Limitations}

A number of factors presented challenges for screening, interpreting findings, pooling results, drawing inferences and evaluating the generalisability of the research findings. These included potentially not identifying all relevant literature, and not having independent, dual screening of articles and extraction of findings. However, these are processes associated with systematic reviews and not with a narrative review. Inconsistencies were found in title (e.g. advanced practice physiotherapist, extended scope practitioner), terminology (including "advanced practice", "extended scope", and "expanded scope"), across the jurisdictions and clinical settings in which the reviewed studies were set, and a lack of clarity or consistency of role or qualifications, reflecting the challenges experienced by previous reviews (Desmeules et al., 2012; Saxon et al., 2014; Stanhope, Beaton, et al., 2012; Stanhope, Grimmer-Somers, et al., 2012). The advanced physiotherapy roles in different jurisdictions variously included triaging patients referred to medical specialists, ordering imaging, limited prescribing and administering injections.

Very little peer-reviewed literature was found from the New Zealand context. The differences between the New Zealand health system and the other systems within which most of these studies were conducted may alter the New Zealand relevance of findings. For example, many New Zealand physiotherapists already practice as first-contact primary care clinicians, so there may be little added benefit of using APPs to reduce GPs' musculoskeletal caseload (Goodwin \& Hendrick, 2016; Mallett et al., 2014). In addition, most studies identified were in musculoskeletal physiotherapy, limiting the applicability of findings to other physiotherapy fields. 
Research gaps identified

Little or no research was found in the following areas:

- Non-musculoskeletal physiotherapy fields.

- The impact of APP management or care on patient recovery outcomes compared to existing models of care.

- Peer-reviewed studies conducted in New Zealand, including in a private practice context.

- Consumer choice in relation to physiotherapy access in contexts where self-referral occurs.

\section{Recommendations}

Further research is required into health outcomes from advanced physiotherapy models of care and the impact of advanced physiotherapy roles in non-musculoskeletal fields of physiotherapy within the New Zealand context and relating to consumer choice for physiotherapy. Furthermore, consistent terminology and clear definitions need to be developed, along with delineation of healthcare roles within the different contexts.

\section{CONCLUSION}

Advanced physiotherapy roles have the potential to provide benefits to the public and health system, and to assist in new models of health delivery when implemented in innovative, interdisciplinary and non-traditional ways. No negative impacts of APPs working in non-traditional roles were identified. These findings should be interpreted within the context of a narrative review methodology.

\section{KEY POINTS}

1. Implementation of advanced physiotherapy roles in innovative interdisciplinary ways can benefit the public and health system, and assist in new models of health delivery.

2. Benefits found with implementing such roles include reduced wait times for appointments, reduced length of stay, improved access to care, reduced musculoskeletal workloads of other clinicians in primary care and emergency departments, streamlined caseloads of orthopaedic surgeons, and improved patient satisfaction.

3. Inconsistent terminology pertaining to the APP title and role was found across and within jurisdictions and contexts.

\section{DISCLOSURES}

No funding was obtained for this study. All authors were members of the 2017 Physiotherapy Board of New Zealand working group for a potential new advanced scope of practice.

\section{ADDRESS FOR CORRESPONDENCE}

Anna Williams, Physiotherapy New Zealand, PO Box 27386, Wellington 6141, New Zealand. Telephone: +64 48941680. Email: anna.williams@physiotherapy.org.nz

\section{REFERENCES}

Bath, B., Grona, S. L., \& Janzen, B. (2012). A spinal triage programme delivered by physiotherapists in collaboration with orthopaedic surgeons. Physiotherapy Canada, 64(4), 356-366. https://doi.org/10.3138/ptc.201129
Burn, D., \& Beeson, E. (2014). Orthopaedic triage: Cost effectiveness, diagnostic/surgical and management rates. Clinical Governance: An International Journal, 19(2), 126-136. https://doi.org/10.1108/CGIJ-122013-0041

Canadian Interprofessional Health Collaborative. (2010). A national interprofessional competency framework. Vancouver, Canada: College of Health Disciplines, University of British Columbia. Retrieved from https:// www.hhr-rhs.ca/index.php?option=com_mtree\&task=att_download\&link_ $i d=7095 \& c f \_i d=68 \& l a n g=e n$

de Gruchy, A., Granger, C., \& Gorelik, A. (2015). Physical therapists as primary practitioners in the emergency department: Six-month prospective practice analysis. Physical Therapy, 95(9), 1207-1216. https://doi. org/10.2522/ptj.20130552

Desjardins-Charbonneau, A., Roy, J. S., Thibault, J., Ciccone, V. T., \& Desmeules, F. (2016). Acceptability of physiotherapists as primary care practitioners and advanced practice physiotherapists for care of patients with musculoskeletal disorders: A survey of a university community within the province of Quebec. BMC Musculoskeletal Disorders, 17(1), 400. https://doi.org/10.1186/s12891-016-1256-8

Desmeules, F., Roy, J. S., MacDermaid, J. C., Champagne, F., Hinse, O., \& Woodhouse, L. J. (2012). Advanced practice physiotherapy in patients with musculoskeletal disorders: A systematic review. BMC Musculoskeletal Disorders, 13, 107. https://doi.org/10.1186/1471-2474-13-107

Desmeules, F., Toliopoulos, P., Roy, J. S., Woodhouse, L. J., Lacelle, M., Leroux, M., ... Fernandes, J. C. (2013). Validation of an advanced practice physiotherapy model of care in an orthopaedic outpatient clinic. BMC Musculoskeletal Disorders, 14, 162. https://doi.org/10.1186/1471-247414-162

Exton, H., Holmes, C., Scranney, A., \& Hollebon, D. (2014). Allied health service based in the emergency department linking the primary and secondary health sectors. Paper presented at the Physiotherapy New Zealand Conference, Auckland, New Zealand.

Goodwin, R. W., \& Hendrick, P. A. (2016). Physiotherapy as a first point of contact in general practice: A solution to a growing problem? Primary Health Care Research \& Development, 17(5), 489-502. https://doi. org/10.1017/S1463423616000189

Greenhalgh, T., Thorne, S., \& Malterud, K. (2018). Time to challenge the spurious hierarchy of systematic over narrative reviews? European Journal of Clinical Investigation, 48(6), e12931. https://doi.org/10.1111/eci.12931

Harding, P., Prescott, J., Block, L., O'Flynn, A. M., \& Burge, A. T. (2015) Patient experience of expanded-scope-of-practice musculoskeletal physiotherapy in the emergency department: A qualitative study. Australian Health Review, 39(3), 283-289. https://doi.org/10.1071/ $\mathrm{AH} 14207$

Hawke, C., Passalent, L., Morton, R., Alnaqbi, K., Haroon, N., Wolman, S., ... Inman, R. (2013). A novel approach to the early detection of axial spondyloarthritis in patients with inflammatory bowel disease: The implementation of an advanced practice physiotherapist led screening program. Annals of the Rheumatic Diseases, 72(Suppl 3), 950.

Jones, A., Powell, T., Watkins, D., \& Kelly, D. (2015). Realising their potential? Exploring interprofessional perceptions and potential of the advanced practitioner role: A qualitative analysis. BMJ Open, 5, e009740. https://doi. org/10.1136/bmjopen-2015-009740

Kennedy, D. M., Robarts, S., \& Woodhouse, L. (2010). Patients are satisfied with advanced practice physiotherapists in a role traditionally performed by orthopaedic surgeons. Physiotherapy Canada, 62(4), 298-305. https:// doi.org/10.3138/physio.62.4.298

Kerridge-Weeks, M., \& Langridge, N. J. (2016). Orthopaedic spinal triage: An evaluation of decision making and outcome in a physiotherapy-led service. International Journal of Health Governance, 21(1), 5-17. https://doi. org/10.1108/IJHG-08-2015-0026

Lefmann, S. A., \& Sheppard, L. A. (2014). Perceptions of emergency department staff of the role of physiotherapists in the system: A qualitative investigation. Physiotherapy, 100(1), 86-91. https://doi.org/10.1016/j. physio.2013.08.004 
MacKay, C., Davis, A. M., Mahomed, N. N., \& Badley, E. M. (2012). A single group follow-up study of non-surgical patients seen by physiotherapists working in expanded roles in orthopaedic departments: Recall of recommendations, change in exercise and self-efficacy. BMC Research Notes, 5, 669. https://doi.org/10.1186/1756-0500-5-669

Mallett, R., Bakker, E., \& Burton, M. (2014). Is physiotherapy self-referral with telephone triage viable, cost-effective and beneficial to musculoskeletal outpatients in a primary care setting? Musculoskeletal Care, 12(4), 251 260. https://doi.org/10.1002/msc. 1075

McClellan, C. M., Cramp, F., Powell, J., \& Benger, J. R. (2012). A randomised trial comparing the clinical effectiveness of different emergency department healthcare professionals in soft tissue injury management. BMJ Open, 2(e001092), 1-10. https://doi.org/10.1136/ bmjopen-2012-001092

McClellan, C. M., Cramp, F., Powell, J., \& Benger, J. R. (2013). A randomised trial comparing the cost effectiveness of different emergency department healthcare professionals in soft tissue injury management. BMJ Open, 3(1), e001116. https://doi.org/10.1136/bmjopen-2012-001116

Ministry of Health. (2016). New Zealand health strategy: Future direction. Retrieved from http://www.health.govt.nz/system/files/documents/ publications/new-zealand-health-strategy-futuredirection-2016-apr16.pdf

Morris, J., Grimmer, K., Gilmore, L., Perera, C., Waddington, G., Kyle, G., . Murphy, K. (2014). Principles to guide sustainable implementation of extended-scope-of-practice physiotherapy workforce redesign initiatives in Australia: Stakeholder perspectives, barriers, supports, and incentives. Journal of Multidisciplinary Healthcare, 7, 249-258. https://doi. org/10.2147/JMDH.S59473

Morris, J., Vine, K., \& Grimmer, K. (2015). Evaluation of performance quality of an advanced scope physiotherapy role in a hospital emergency department. Patient Related Outcome Measures, 6, 191-203. https://doi. org/10.2147/PROM.S75173

Naik, L. (2016). New horizons for future physiotherapy roles: Orthopaedic triage physiotherapists. Paper presented at the Physiotherapy New Zealand Conference, Auckland, New Zealand.

Napier, C., McCormack, R. G., Hunt, M. A., \& Brooks-Hill, A. (2013). A physiotherapy triage service for orthopedic surgery: An effective strategy for reducing wait times. Physiotherapy Canada, 65(4), 358-363. https:// doi.org/10.3138/ptc.2012-53

O Mir, M., Cooney, C., O'Sullivan, C., Blake, C., Kelly, P., Kiely, P., . . Moore, D. (2016). The efficacy of an extended scope physiotherapy clinic in paediatric orthopaedics. Journal of Children's Orthopaedics, 10(2), 169175. https://doi.org/10.1007/s11832-016-0725-9

Oakley, C., \& Shacklady, C. (2015). The clinical effectiveness of the extendedscope physiotherapist role in musculoskeletal triage: A systematic review. Musculoskeletal Care, 13(4), 204-211. https://doi.org/10.1002/msc.1100

Passalent, L., Hawke, C., Omar, A., Alnaqbi, K., Wallis, D., Haroon, N., \& Inman, R. D. (2015). A comparison of interobserver agreement between advanced practice physiotherapists and rheumatologists in the detection of axial spondyloarthritis. Arthritis \& Rheumatology, 67(Suppl 10), 38763877.

Phillips, C. J., Phillips, R., Main, C. J., Watson, P. J., Davies, S., Farr, A., . . Hale, J. (2012). The cost effectiveness of NHS physiotherapy support for occupational health $(\mathrm{OH})$ services. BMC Musculoskeletal Disorders, 13, 29. https://doi.org/10.1186/1471-2474-13-29
Physiotherapy Board. (n.d.). The scopes of physiotherapy. Retrieved from https://www.physioboard.org.nz/i-am-registered/scopes-of-practice

Physiotherapy Board. (2017). Update on the general scope review and options for an advanced scope of physiotherapy practice. September 2017 Physiotherapy Board Newsletter. Retrieved from https:// mailchi.mp/5cc8c06ef962/physiotherapy-board-newsletter-may$606893 ? \mathrm{e}=[$ UNIQID]

Physiotherapy Board. (2018). Advanced practice physiotherapist - scope of practice. April 2018 Physiotherapy Board Newsletter. Retrieved from https://mailchi.mp/physioboard.org.nz/physiotherapy-board-newslettermay-606969?

Razmjou, H., Robarts, S., Kennedy, D., McKnight, C., MacLeod, A. M., \& Holtby, R. (2013). Evaluation of an advanced-practice physical therapist in a specialty shoulder clinic: Diagnostic agreement and effect on wait times. Physiotherapy Canada, 65(1), 46-55. https://doi.org/10.3138/ptc.2011-56

Samsson, K., Bernhardsson, S., \& Larsson, M. E. H. (2016). Perceived quality of physiotherapist-led orthopaedic triage compared with standard practice in primary care: A randomised controlled trial. BMC Musculoskeletal Disorders, 17, 257. https://doi.org/10.1186/s12891-016-1112-x

Samsson, K., \& Larsson, M. E. H. (2014). Physiotherapy screening of patients referred for orthopaedic consultation in primary healthcare - A randomised controlled trial. Manual Therapy, 19(5), 386-391. https://doi. org/10.1016/j.math.2013.10.004

Saxon, R. L., Gray, M. A., \& Oprescu, F. I. (2014). Extended roles for allied health professionals: An updated systematic review of the evidence. Journal of Multidisciplinary Healthcare, 7, 479-488. https://doi. org/10.2147/JMDH.S66746

Schulz, P., Prescott, J., Shifman, J., Fiore, J., Holland, A., \& Harding, P. (2016). Comparing patient outcomes for care delivered by advanced musculoskeletal physiotherapists with other health professionals in the emergency department - A pilot study. Australasian Emergency Nursing Journal, 19(4), 198-202. https://doi.org/10.1016/j.aenj.2016.06.001

Stanhope, J., Beaton, K., Grimmer-Somers, K., \& Morris, J. (2012). The role of extended scope physiotherapists in managing patients with inflammatory arthropathies: A systematic review. Open Access Rheumatology: Research and Reviews, 4, 49-55. https://doi.org/10.2147/OARRR.S31465

Stanhope, J., Grimmer-Somers, K., Milanese, S., Kumar, S., \& Morris, J. (2012). Extended scope physiotherapy roles for orthopedic outpatients: An update systematic review of the literature. Journal of Multidisciplinary Healthcare, 5, 37-45. https://doi.org/10.2147/JMDH.S28891

Warmington, K., Kennedy, C. A., Lundon, K., Soever, L. J., Brooks, S. C., Passalent, L. A., . . . Schneider, R. (2015). The patient perspective: Arthritis care provided by advanced clinician practitioner in Arthritis Care programtrained clinicians. Open Access Rheumatology: Research and Reviews, 7, 45-53. https://doi.org/10.2147/OARRR.S85783

Wiles, L., \& Milanese, S. (2016). Stakeholder perspectives of the extended scope physiotherapy practitioner (ESPP) role in Australia - A qualitative study. Physical Therapy Reviews, 21(3-6), 228-235. https://doi.org/10.108 0/10833196.2016.1256118 